\title{
Pesticide Concentrations in Vacuum Dust from Farm Homes: Variation between Planting and Nonplanting Seasons
}

\author{
Vijay Golla, ${ }^{1}$ Brian Curwin, ${ }^{2}$ Wayne Sanderson, ${ }^{3}$ and Marcia Nishioka ${ }^{4}$ \\ ${ }^{1}$ Department of Public Health, Western Kentucky University, Bowling Green, KY 42101, USA \\ ${ }^{2}$ National Institute for Occupational Safety and Health, Centers for Disease Control and Prevention, 4676 Columbia Parkway MS R-14, \\ Cincinnati, OH 45226, USA \\ ${ }^{3}$ Department of Epidemiology, University of Kentucky College of Public Health, 121 Washington Avenue, Lexington, KY 40536, USA \\ ${ }^{4}$ Center for Public Health Research and Evaluation, Battelle Memorial Institute, 505 King Avenue, Columbus, OH 43201, USA
}

Correspondence should be addressed to Vijay Golla, vijay.golla@wku.edu

Received 27 October 2011; Accepted 30 November 2011

Academic Editors: I. Szadkowska-Stanczyk and G. Truchon

Copyright ( 2012 Vijay Golla et al. This is an open access article distributed under the Creative Commons Attribution License, which permits unrestricted use, distribution, and reproduction in any medium, provided the original work is properly cited.

\begin{abstract}
The hazards of chronic low-level pesticide exposures inside homes have received little attention. Research to date does not provide answers regarding the long-term potential bioavailability of pesticides in homes and its risk factors. The purpose of this study was to investigate pesticide levels in Iowa homes during one year and assess the relationship between exposure levels and potential sources of pesticide contamination. The study involved sampling surveys of the target pesticide atrazine among 32 farm families in a three-county area of Iowa during the planting season (April-June) and nonplanting season (November-December). Dust samples were collected, and information gathered through questionnaires to evaluate pesticide migration inside homes. This study found that dust in every farm home surveyed was contaminated with atrazine during both seasons and these concentrations significantly decreased by the nonplanting season. Pesticide amounts, acreage, and spraying time determined the presence and persistence of this herbicide inside farm homes.
\end{abstract}

\section{Introduction}

Agricultural chemicals used on farms include a wide variety of pesticides such as herbicides, insecticides, fungicides, and rodenticides. The annual pesticide application in the United States is approximately 544 million kilograms [1]. Of all these, the most used are herbicides: approximately $46 \%$ of all the pesticides [1]. In 1999, this usage constituted approximately 249 million kilograms. Farmers are the largest group of registered pesticide applicators according to the Agricultural Health Study [2]. Farmers are at risk of direct exposure during handling, mixing, loading, and application of pesticides and maintenance of equipment.

Pesticides can be transported into homes soon after spraying [3] and family members may be exposed through home contamination even though they did not participate in farming activities [4]. Homes near farm operations where pesticides are used may be contaminated via air, shoes and clothing, or pets [5]. Studies have found that farm homes have a greater frequency of detectable concentrations of pes- ticides and higher levels in dust than in nonfarm homes [68].

Because of growth and cell development and their smaller body weight, exposure of children to pesticides is a serious concern $[9,10]$. The Natural Resources Defense Council (NRDC) considers pesticides to be one of the top five environmental concerns to children's health and farm children are especially at risk of exposure [11].

A study of children's pesticide exposures in an orchard growing area of Washington state found that one-sixth of the children had detectable levels of organophosphates (OP) on their hands compared to none in the reference population. Also, $35 \%$ of agricultural children exceeded the EPA's acute reference dose for azinphos-methyl of $3 \mu \mathrm{g} / \mathrm{kg}$ body weight/day [9]. A study of the distribution of 2,4-D in the air and on surfaces inside residences after lawn applications in Columbus, Ohio in which exposure estimates from various media for young children were compared, found that 2,4-D was detected in indoor air and on all surfaces throughout all homes. Resuspension of floor dust was the major source of 
2,4-D in indoor air, with highest levels found in the particle size range of $2.5-10 \mu \mathrm{m}$. These levels were estimated to be about 10 times higher than the preapplication exposures [12]. A study of pesticide contamination in rural children's homes in California found that 10 of 33 pesticides were detected in house dust. Concentrations of diazinon and chlorpyrifos were higher in farm worker homes than nonfarm worker homes, suggesting that children's exposure to diazinon could exceed the EPA's chronic reference dose [6]. A study by Curl et al. [13] found that the take-home exposure pathway contributes to residential pesticide contamination in agricultural homes where young children are present.

Study of the risk of adverse health effects from pesticide exposures requires an understanding of the specific agricultural chemicals used, routes of exposure, toxicity, duration of exposure, and the absorbed doses. The specific work characteristics of the individuals involved in these agricultural practices and their use of protective equipment are important in assessing pesticide exposures and the potential for adverse health effects. In spite of significant research being carried out to characterize exposures in different agricultural settings, research data for risk estimation and characterization are not adequate [14]. Residues from recently sprayed pesticides can show up in dust, however, dust can also act as a reservoir for pesticides used on a long-term basis and even for pesticides that are no longer used but are environmentally persistent $[3,6,15,16]$.

In 2001, NIOSH conducted a study of in-home pesticide levels in 25 farm and 25 nonfarm homes in Iowa [17, 18]. Air, surface wipe, and vacuum dust samples were collected from these homes and analyzed for the presence of several pesticides: acetochlor, alachlor, chlorpyrifos, 2,4-D, atrazine, metolachlor, and glyphosate. Chlorpyrifos, glyphosate, and 2,4-D were found in air, surface wipe, and dust samples in both farm and nonfarm homes. However, higher levels of atrazine and metolachlor were found in the samples collected from locations in the homes where farmers entered or changed clothes indicating that these pesticides were brought into the home on the their shoes and clothing. Since acetochlor was sprayed by only a few farmers and alachlor was not sprayed at all, these pesticides were not detected frequently in this study. Curwin et al. [17] found that pesticide concentrations were detected on a very few of the wipe samples and that vacuum dust samples were the best matrix for measuring pesticide contamination inside homes. These results are also supported by work conducted in Minnesota [19].

Curwin et al. [17, 18] also concluded that household characteristics such as age of the carpet, frequency of carpet vacuuming, presence of doormats, presence of pets, and age of the homes were not associated with pesticide levels in dust. The pesticide levels in this study were also not correlated with distance of pesticide-treated fields from the nonfarm homes. The distance to the fields was not analyzed for the farm homes since they were all located less than quarter of a mile from treated fields. This study concluded that farm homes have higher concentrations of pesticides than nonfarm homes and farmers who sprayed a particular pesticide have higher concentrations of that pesticide inside their homes than where occupants did not spray that pesticide. This finding was more specific to atrazine and metolachlor than the other pesticides under study, but those were the most commonly used of the seven pesticides $[17,18]$.

Specific risk factors affecting in-home pesticide levels were not determined in Curwin's study $[17,18]$ and it was only conducted during the planting season. However, the study laid the foundation for the current study by focusing it on one of the more commonly used pesticides, atrazine, guiding investigation of factors that might be associated with in-home migration and measuring concentrations several months after the application season had ended. The objective of the current study was to evaluate concentrations of atrazine in vacuum dust samples from farm family homes in Iowa and assess the association between various factors, such as amount of atrazine used and family hygienic practices, and atrazine levels in the dust, and to study the changes in pesticide concentrations in farm homes over time.

\section{Methods}

2.1. Study Design. Environmental pesticide levels were assessed by collecting vacuum dust samples from four locations within the homes: entryway, living room, master bedroom, and kitchen. The samples were only analyzed for the herbicide atrazine. In addition, information was gathered through questionnaires and by observation to document information about the home, pesticide usage in and around the home, application techniques, work practices, use of personal protective equipment (PPE), and procedures for handling and cleaning work clothing.

2.2. Study Population and Recruitment. Subjects were recruited by contacting families living on a farm and designated in the Iowa Agricultural Census as farming at least 100 acres of tillable cropland in Cedar, Iowa, or Johnson counties. Before contacting study subjects, the project underwent appropriate human subjects review by The University of Iowa (UI) and National Institute for Occupational Safety and Health (NIOSH) Human Subjects Review Boards (HSRB). The farmers' information was acquired through the county plat books of the three counties under study. A total of 242 homes were randomly selected and sent an initial letter describing the study and requesting their participation. Individuals who refused to participate returned a "do not call statement" that was included along with the initial letter; $130(54 \%)$ of the 242 homes that were sent the initial letter declined to participate in this study. Those individuals from whom this statement was not received were called within a period of two weeks of sending the initial contact letter; 32 of the remaining 112 homes met the requirement of planning to apply atrazine during the planting season and agreed to participate in the study. During the first visit, the investigator explained the study, answered questions, and obtained informed consent to participate. Each house was visited twice-once during the planting season (AprilJune) and once approximately six months after the planting season (nonplanting season, November-December) of 2005. 
Farmers were given a telephone number to call study personnel to inform them that pesticide spraying had begun and the first visit was scheduled within a few days after atrazine was applied to cropland. The second visit was basically a repeat of the first visit except the questionnaire was modified to collect information about postplanting spraying of atrazine.

2.3. Sample Methods. Dust samples were collected from carpets using a high-volume surface sampler (HVS-3, Cascade Stamp Sampling Systems) following the American Society for Testing Material (ASTM) Standard Practice for Collection of Dust from Carpeted Floors for Chemical Analysis [20]. Briefly, the method involved sampling a measured area of approximately one square meter. The vacuum sampler, which contains a cyclone and a catch bottle, was passed over a strip of carpet in a straight line back and forth four times. This process was repeated with subsequent adjacent strips until the desired area had been sampled. A minimum of 0.5 grams of dust was desired, but care was taken to avoid filling up the cyclone catch bottle. If the desired amount of dust was not collected, an adjacent $1 \mathrm{~m}^{2}$ area was sampled. If not enough area existed to collect a sufficient quantity of dust for analysis, then dust samples from adjacent locations had to be combined to ensure a sufficient quantity of dust. A new catch bottle was used for each sample. Between the four sample locations within each home and between homes, the vacuum and cyclone were cleaned with isopropanol to ensure that there was no contamination of samples. Dust samples were collected from carpets in the entryway, living room, master bedroom, and kitchen. Every effort was made to keep the four different locations constant over the 32 households. However, there was variation in location for a few homes. For example, some homes had an entryway that led directly into the living room. Some others had an entryway through the garage door. Some farmers were using the garage door entryway to get into the house, while some others used the front door to enter directly into the living room, and others entered the home through the kitchen. The location that the farmer entered the house from was recorded as the entryway and kept constant throughout the study.

2.4. Analytical Method for Analysis of Atrazine in Dust. The dust samples were sieved to $150 \mu \mathrm{m}$ using a 100 mesh stainless steel sieve. A $0.5 \mathrm{~g}$ aliquot of each fine dust sample was weighed out and spiked with $250 \mathrm{ng}$ of the surrogate recovery standard (SRS) ${ }^{13} \mathrm{C}_{3}$-atrazine. The dust was extracted using ultrasonication in $12 \mathrm{~mL}$ of $1: 1(\mathrm{v}: \mathrm{v})$ hexane : acetone. From the $12 \mathrm{~mL}$ extract, $10 \mathrm{~mL}$ was drawn off and concentrated to $1 \mathrm{~mL}$. An additional aliquot of $5 \mathrm{~mL}$ of hexane was added, and the extract was reconcentrated to $1 \mathrm{~mL}$. A $1000 \mathrm{mg}$ silica SPE cartridge (BakerBond, JT Baker) was conditioned in sequence with $20 \%$ acetone in ethyl acetate, dichloromethane (DCM), 15\% ethyl ether in hexane, and hexane. The sample extract was added to the cartridge with hexane rinses and eluted with the same solvents in reverse order. The eluent from the first three solvents was discarded; the acetone in ethyl acetate elution was collected, concentrated to $1 \mathrm{~mL}$, and spiked with the internal standard (IS) for quantification, dibromobiphenyl.

Each sample batch included 10 field samples, one field sample analyzed in duplicate, a field sample spiked with either 25,250 or $2500 \mathrm{ng}$ of atrazine, and a solvent method blank fortified with only the SRS. The extracts and standards were analyzed using gas chromatography/mass spectrometry in the multiple ion detection mode (GC/MS/MID) with an HP 6890 GC interfaced to an HP 5973 MSD. A 30 m ZB-35 (Phenomenex; $0.25 \mathrm{~mm}$ id $\times 0.25 \mu \mathrm{m}$ film) GC column was used, with the temperature programmed from $160-280^{\circ} \mathrm{C}$ at $6^{\circ} \mathrm{C} / \mathrm{min}$. The internal standard method of quantification was used, with a linear regression calibration curve established for atrazine and the SRS. For samples where the atrazine exceeded the calibration range, the sample extract was diluted, respiked with IS, and reanalyzed. The recovery of ${ }^{13} \mathrm{C}_{3}$ atrazine in the field samples averaged $86 \pm 11 \%$. With the exception of one sample where atrazine was not detected, atrazine was present in all samples at levels above the Limit of Detection (LOD; $2.5 \mathrm{ng} / \mathrm{g}$ ). The concentrations of atrazine ranged from 3 to $593,111 \mathrm{ng} / \mathrm{g}$ in the field samples. SRS-corrected atrazine concentrations were used for data analysis in this study.

Recoveries of atrazine in fortified samples were $99 \pm 3 \%$ (50 ng/g; $n=5), 103 \pm 2 \%(500 \mathrm{ng} / \mathrm{g} ; n=4)$, and $76 \pm 9 \%$ (5000 ng/g; $n=5$ ). Levels of atrazine in field blanks (empty HVS3 catch bottles) were equivalent to $0.2 \pm 1.1 \mathrm{ng} / \mathrm{g}(n=$ $15)$. The average relative percent difference for duplicate samples was $19 \%(n=12)$.

2.5. Data Analysis. Atrazine concentrations were reported in nanograms per gram of dust (ng/g) for the vacuum samples. The study examined the relationship between family member's pesticide exposure, home pesticide contamination, and factors influencing pesticide contamination. Descriptive summary statistics were used to describe the central tendency and variance of each variable measured. Analysis of variance (ANOVA) and multivariate analysis were used to determine if selected farm and personal practices influenced home contamination. The data collected from the interview were coded and analyzed to determine if any relationship exists between exposure and selected variables, and which of these variables affected home contamination and exposure the most. The variables that were considered included the number of acres of corn grown, the amount of atrazine applied, the age of the home, the age of the carpet, the number of hours of atrazine application, the number of days of atrazine application, how often the carpet was vacuum-cleaned, whether the family owned a pet, application of any other pesticides inside the home, on the lawn or garden, change of clothes and shoes inside the home, laundering of clothes separately, and if the homes were located less than half a mile from the crop fields. The $t$-statistic was used to compare the difference in pesticide contamination and family exposure between farm homes that did their own spraying and those that hired a commercial applicator for spraying their fields. The vacuum samples were compared with each other for all four locations in the home for farmer-applied and commercial applicator-applied homes during both the planting 
TABLE 1: Atrazine application by type of pesticide applicator.

\begin{tabular}{|c|c|c|c|c|c|}
\hline & \multicolumn{2}{|c|}{ Farmer applicator $(n=10)$} & \multicolumn{2}{|c|}{ Commercial applicator $(n=22)$} & \multirow{2}{*}{$P$ value $^{\mathrm{a}}$} \\
\hline & Mean (SD) & Range & Mean (SD) & Range & \\
\hline Avg. No. of Acres & $381(273.7)$ & $80-850$ & $289(233.2)$ & $50-900$ & 0.33 \\
\hline Atrazine (kgs) & $379(272)$ & $79-845$ & $376(304)$ & $65-1172$ & 0.97 \\
\hline No. of days applied & $5(4)$ & $1-15$ & $5(12.2)$ & $1-60$ & 0.95 \\
\hline $\begin{array}{l}\text { No. of hours } \\
\text { applied }\end{array}$ & $7.3(2.8)$ & $2-12$ & $5(3.3)$ & $1-14$ & 0.05 \\
\hline
\end{tabular}

${ }^{a}$ Student's $t$-test with $P$ value $<0.05$ considered statistically significant.

TABLE 2: Atrazine spraying intervals for planting and nonplanting seasons.

\begin{tabular}{|c|c|c|c|c|c|c|}
\hline & \multicolumn{3}{|c|}{ Planting season (April-July) } & \multicolumn{3}{|c|}{ Nonplanting season (Nov-Dec) } \\
\hline & Interval (days) & No. of homes & $\%$ of homes & Interval $^{\mathrm{a}}$ (days) & No. of homes & $\%$ of homes \\
\hline \multirow{4}{*}{$\begin{array}{l}\text { Number of days between end } \\
\text { of atrazine application and } \\
\text { sample collection }\end{array}$} & 0 & 4 & 12 & $188-190$ & 7 & 22 \\
\hline & $1-2$ & 6 & 19 & $191-200$ & 8 & 25 \\
\hline & $3-4$ & 6 & 19 & $201-210$ & 2 & 6 \\
\hline & $5-6$ & 16 & 50 & $211-219$ & 15 & 47 \\
\hline \multirow{4}{*}{$\begin{array}{l}\text { Number of days atrazine } \\
\text { applied to cropland before } \\
\text { sample collection }\end{array}$} & $1-2$ & 11 & 35 & $1-2$ & 12 & 38 \\
\hline & $3-4$ & 9 & 28 & $3-4$ & 3 & 9 \\
\hline & $5-6$ & 3 & 9 & $5-6$ & 0 & 0 \\
\hline & $>6$ & 9 & 28 & $>6$ & 0 & 0 \\
\hline
\end{tabular}

${ }^{a}$ Interval (days) in the nonplanting season represents the number of days between end of atrazine application in the planting season and sample collection in the nonplanting season.

and nonplanting seasons to determine the best indicator of pesticide exposure and to see if any correlation existed between the samples. All statistical analyses were performed using SAS system software, version 9.1 (SAS Institute, Inc., Cary, NC). All significance testing was performed at the 0.05 level of significance.

\section{Results}

A total of 32 families were recruited where atrazine was applied to their farmland. This included ten farm families that had children 15 years old or less living in their household. A total of 73 subjects participated, of which 40 were male and 33 were female. Atrazine was applied to the corn fields by either the farmers (10 farm homes) or commercial applicators (22 farm homes). Ground boom application of pesticides was used by all the farm households. The average age of the farmers in this study was 60 years.

The average number of acres sprayed, the duration of application, and the amount of atrazine used are displayed in Table 1. There were no significant differences in the number of acres sprayed, pounds of atrazine applied, or days applied between farm homes where atrazine was applied by farmers themselves and those where it was applied by commercial applicators. However, the farmers spent on average $50 \%$ more time applying atrazine to their land than did the commercial applicators.

The average number of acres (mean $=216$, sd $=123$; obtained from the county plat books) farmed by the remaining 80 homes of the 112 homes that were willing to participate in the study, but were not scheduled is significantly lower than the average number of acres (mean $=318$, sd $=246$ ) farmed by the 32 study homes that were recruited $(P$ value $=$ $0.03)$. The average age of the farmers in this study was less, but not significantly different than the average age of the farmers (mean $=65$ years) who refused to participate in the study $(P=0.08)$. This age information was obtained through internet search of public information.

The number of days between the end of atrazine application and sample collection and the total number of days atrazine was applied before sample collection are presented in Table 2 by planting and nonplanting seasons. During planting season, samples were collected in half the homes within four days of the end of atrazine application and from 5 to 6 days after the end of application in the remaining half. For $35 \%$ of the homes atrazine was applied for only one or two days before samples were collected and for $28 \%$ of the homes atrazine was applied for three or four days. During nonplanting season, no samples were collected less than six months (183 days) after the end of atrazine application and all samples were collected before 220 days ( 7.2 months) after the end of application. Between the time of sample collection during planting season and the time of sample collection during the nonplanting season, only $47 \%$ of the homes had additional days on which atrazine was applied-on $38 \%$ atrazine was applied for one or two days and on 9\% atrazine was applied for three or four days.

Household characteristics potentially associated with atrazine levels in dust are presented in Table 3. There were no significant differences for any of these characteristics between 
TABLE 3: Household characteristics of farm families by type of pesticide applicator.

\begin{tabular}{|c|c|c|c|c|c|}
\hline \multirow{2}{*}{ Household characteristics } & \multicolumn{2}{|c|}{ Farmer applicator } & \multicolumn{2}{|c|}{ Commercial applicator } & \multirow{2}{*}{$P$ value $^{\mathrm{a}}$} \\
\hline & Mean (SD) & Range & Mean (SD) & Range & \\
\hline Age of home (years) & $61(56.7)$ & $2-166$ & $60(42.5)$ & $7-146$ & 0.95 \\
\hline \multirow[t]{2}{*}{ Age of carpet (years) } & $37(26.1)$ & $2-86$ & $49(33.4)$ & $7-106$ & 0.30 \\
\hline & No. of Homes & \% Homes & No. of Homes & \% Homes & $P$ value $^{\mathrm{a}}$ \\
\hline Any pesticide applied inside home within past year & 5 & 16 & 8 & 25 & 0.46 \\
\hline Lawns treated with any pesticide within past year & 4 & 13 & 10 & 31 & 0.77 \\
\hline Garden treated with any pesticide within past year & 3 & 9 & 10 & 31 & 0.40 \\
\hline Carpet vacuumed at least once a week & 8 & 25 & 20 & 63 & 0.38 \\
\hline Presence of Doormats & 9 & 28 & 21 & 66 & 0.55 \\
\hline Presence of Pets & 9 & 28 & 16 & 50 & 0.27 \\
\hline Distance of the home from the farm $<0.5$ miles & 10 & 31 & 21 & 66 & 0.49 \\
\hline Launder clothes separate from rest of the family & 5 & 16 & 14 & 44 & 0.46 \\
\hline Change work clothes inside the home & 7 & 22 & 14 & 44 & 0.72 \\
\hline Change shoes inside the home & 7 & 22 & 11 & 34 & 0.29 \\
\hline Homes with Children & 3 & 22 & 5 & 25 & 0.13 \\
\hline
\end{tabular}

${ }^{\text {a }} P$ value $<0.05$ is obtained from Chi-Square test is statistically significant.

TABLE 4: Atrazine concentrations in dust samples by location within homes and season in nanograms per gram dust (ng/g).

\begin{tabular}{lcccc}
\hline \multirow{2}{*}{ Location } & \multicolumn{2}{c}{ Planting season $n=31$ homes } & \multicolumn{2}{c}{ Nonplanting season $n=31$ homes } \\
& GM $($ GSD $)$ & Range & GM (GSD) & $47(9.1)^{\mathrm{b}}$ \\
\hline Entryway & $687(11.4)^{\mathrm{a}}$ & $5-139,200$ & $30(7.3)^{\mathrm{b}}$ & $1-1,900$ \\
Living Room & $285(15.3)^{\mathrm{a}}$ & $1-1,268,000$ & $19(7.1)^{\mathrm{b}}$ & $1-2,300$ \\
Master Bedroom & $307(9.2)^{\mathrm{a}}$ & $10-22,500$ & $41(11.8)^{\mathrm{b}}$ & $1-3,630$ \\
Kitchen & $566(10.6)^{\mathrm{a}}$ & $27-697,750$ & $33(7.1)$ & $1-15,225$ \\
House Avg. & $422(7.4)$ & $1-1,268,000$ & $1-15,225$ \\
\hline
\end{tabular}

a, b Geometric means with the same letter are not significantly different from each other based on $P$ value $<0.05$ obtained from ANOVA Duncan's Multiple Range Test.

farmers who sprayed their fields with atrazine compared with farmers whose fields were sprayed by commercial applicators.

A total of 256 dust samples were obtained from the carpet, rugs, and floors of the farmers' homes during both the planting and nonplanting season. However, three of the four samples of one home for which a commercial applicator had applied atrazine in the planting season were lost during shipment to the laboratory and the dust samples from that home (both planting and nonplanting season's samples $=8$ ) were not included in any further analyses. Therefore the total number of samples available for analysis was 248 . The dust levels were log-normally distributed, therefore the natural log values of these measurements were used in the ANOVA and the geometric means and standard deviations of the measurements were presented in the tables.

In some locations within some homes it was easy to collect approximately one gram of vacuum dust within one square meter. However, in other homes and locations much larger surface areas had to be vacuumed in order to collect sufficient dust for analysis. Presenting the atrazine levels in units of nanograms per gram (ng/g) of dust collected indicates the amount of atrazine present in the household dust load. Presenting the concentration of atrazine as nanograms per square centimeter $\left(\mathrm{ng} / \mathrm{cm}^{2}\right)$ of floor is a function of the amount of vacuum dust available over some surface area. Therefore, the concentrations presented in $\mathrm{ng} / \mathrm{cm}^{2}$ are affected by the relative cleanliness of the homes or how often the floors were cleaned. The atrazine concentrations in the dust samples are presented in both units (Tables 4 and 5). However, when evaluating the association between various factors that might influence in-home migration of pesticides, atrazine levels in units of ng/gm were used (Table 6).

During the planting season, the entryways and the kitchens had the greatest concentrations of atrazine in the dust samples, geometric mean of $687 \mathrm{ng} / \mathrm{g}$ and $566 \mathrm{ng} / \mathrm{g}$, respectively (Table 4 ). The living rooms (or rooms in which the family spent most of their time together) and the master bedrooms had similar atrazine concentrations, geometric mean of $285 \mathrm{ng} / \mathrm{g}$ and $307 \mathrm{ng} / \mathrm{g}$, respectively, but they were not significantly lower than the concentrations in the entryways and kitchens. The concentration of atrazine in the household dust samples decreased by greater than an order of magnitude between the planting and nonplanting seasons, but atrazine was still detectable in all of the dust samples. The planting season atrazine concentrations were significantly higher 
TABLE 5: Atrazine concentrations in dust samples by location within the homes and season in nanograms per square centimeter $\left(\mathrm{ng} / \mathrm{cm}^{2}\right)$.

\begin{tabular}{|c|c|c|c|c|}
\hline \multirow{2}{*}{ Location } & \multicolumn{2}{|c|}{ Planting } & \multicolumn{2}{|c|}{ Nonplanting } \\
\hline & GM (GSD) & Range & GM (GSD) & Range \\
\hline Entryway & $0.40(21.0)^{\mathrm{a}}$ & $0.002-87$ & $0.015(16.4)^{\mathrm{c}, \mathrm{d}}$ & $4.7 \mathrm{E}-5-5$ \\
\hline Living Room & $0.033(14)^{\mathrm{c}}$ & $4.4 \mathrm{E}-5-8$ & $0.003(11.3)^{\mathrm{e}}$ & $6.2 \mathrm{E}-6-0.4$ \\
\hline Master Bedroom & $0.045(7.1)^{\mathrm{b}, \mathrm{c}}$ & $0.002-3$ & $0.003(10.3)^{e}$ & $6.1 \mathrm{E}-5-1$ \\
\hline Kitchen & $0.14(17.7)^{\mathrm{a}, \mathrm{b}}$ & $0.002-652$ & $0.008(37)^{\mathrm{d}, \mathrm{e}}$ & $4 \mathrm{E}-6-63$ \\
\hline House Avg. & $0.09(8.6)$ & $0.002-652$ & $0.006(11.0)$ & $4 \mathrm{E}-6-63$ \\
\hline
\end{tabular}

than the nonplanting season atrazine concentrations for all locations $(P$ value $<0.05)$.

The geometric mean household dust concentrations across all four sampling locations were $422 \mathrm{ng} / \mathrm{g}$ and $33 \mathrm{ng} / \mathrm{g}$ in the planting and nonplanting seasons, respectively.

In Table 5, the summary statistics of the atrazine concentrations for both planting and nonplanting seasons are presented in nanograms of atrazine per square centimeter of floor sampled $\left(\mathrm{ng} / \mathrm{cm}^{2}\right)$. Comparing within the planting season, atrazine concentrations from the entryway were significantly higher than those in the master bedroom and living room, but not the kitchen. Concentrations from the master bedroom and living rooms were similar. Comparing within the nonplanting season, atrazine concentrations from the entryway were significantly higher than those in the master bedroom, and the living room. Atrazine measurements in th e nonplanting season were all significantly lower than the measurements in the planting season.

Comparison of in-home atrazine levels by household and farmer characteristics are presented in Table 6 for differences during the planting and nonplanting seasons. The ages of the homes and duration farm families had lived there did not show that older homes that had been inhabited longer had higher levels of atrazine. However, farmers with more cropland tended to have newer homes. Also, nearness to cropland did not show an association with in-home atrazine levels, but all homes were within a few hundred yards of cropland and none were located in a town or city.

As farm families applied more atrazine, reflected by the number of acres of corn sprayed and time spent mixing and applying atrazine, the amount of atrazine inside their homes tended to increase as well. This was also true for the amount of soybean acreage and time spent mixing and applying pesticides to soybean crops. Although atrazine is not usually applied to soybeans, the farmers who had more soybean acreage also tended to have more corn acreage. The atrazine levels inside the home of farmers who applied atrazine themselves were higher than inside the homes of farm families who hired commercial applicators to apply atrazine.

Factors which were expected to reduce the amount of atrazine migrating into homes, such as use of cabbed tractors, wearing protective gloves, long pants, long-sleeved shirts, and changing clothes and shoes outside the home, showed no association or were even associated with somewhat higher levels of atrazine inside the home.

\section{Discussion}

This study found that farmers' homes were contaminated with the herbicide atrazine during the planting season, particularly at the entryways and kitchens-high-traffic areas which are first entered by the families. Detectable concentrations of atrazine remained in the homes in the nonplanting season; however, the in-home atrazine concentrations had significantly decreased by about six months after planting season. The atrazine concentrations in farm homes were comparable to pesticide concentrations found in farm homes in the studies conducted by Curwin et al., [17], Simcox et al. [8], and Bradman et al., [6]. These studies measured significantly higher pesticide concentrations in dust samples in farm homes compared to nonfarm homes, but only collected samples during the planting seasons.

The farmers in this study who applied atrazine themselves, instead of hiring a commercial applicator to apply it, and who applied atrazine to more cropland, had greater concentrations of atrazine inside their homes. The only other factor that appeared to be related to increased concentrations of atrazine was allowing pet dogs to come inside the homes. These findings are consistent with Curwin et al. [21] that showed children of farmers who applied their own atrazine had higher urinary atrazine metabolite concentrations than children on farms where commercial applicators applied the atrazine. However, even when atrazine was commercially applied, the results showed that atrazine contamination is occurring in house dust, suggesting that atrazine is transported into the homes even if the farmer, has not been directly involved in pesticide mixing, loading and spraying.

According to a study conducted in England, Ramwell et al. [22] found that significant pesticide residues remained on the external surfaces of field crop sprayers. The ten farmers in our study who applied atrazine themselves to their fields may have received repeated atrazine exposures when using for other tasks the equipment used to apply pesticides. It is unlikely that the equipment of farmers who did not apply atrazine were directly contaminated. Work practice and personal hygiene factors which were expected to have been associated with reduced concentrations of inhome atrazine did not show a reduction in in-home atrazine levels. However, these work practices may not have been employed properly, or may have been overwhelmed by other factors influencing the in-home migration of atrazine. Also, 
TABLE 6: Mean atrazine concentrations of four vacuum samples from inside homes by various factors (variables(b)): concentrations in nanograms per gram dust (ng/g).

(a)

\begin{tabular}{|c|c|c|c|c|c|}
\hline \multirow{2}{*}{ Variable } & \multirow{2}{*}{ No. of Households } & \multicolumn{2}{|c|}{ Planting season } & \multicolumn{2}{|c|}{ Nonplanting season } \\
\hline & & GM (GSD) & $P$ value ${ }^{\mathrm{a}}$ & GM (GSD) & $P$ value ${ }^{\mathrm{a}}$ \\
\hline \multicolumn{6}{|l|}{ Year house built } \\
\hline $1840-1930$ & 11 & $152(6.8)$ & \multirow{3}{*}{0.076} & $13(5.7)$ & \multirow{3}{*}{0.137} \\
\hline $1931-1979$ & 10 & $380(4.6)$ & & $47(7.5)$ & \\
\hline 1980-2004 & 10 & $1140(9.9)$ & & $62(6.7)$ & \\
\hline \multicolumn{6}{|c|}{ Year moved into house } \\
\hline 1928-1972 & 11 & $297(8.6)$ & \multirow{3}{*}{0.293} & $35(7.5)$ & \multirow{3}{*}{0.848} \\
\hline 1973-1985 & 10 & $281(6.3)$ & & $23(6.2)$ & \\
\hline 1986-2004 & 10 & $728(9.0)$ & & $42(9.0)$ & \\
\hline \multicolumn{6}{|c|}{ Distance to crop fields } \\
\hline$\leq 75 \mathrm{ft}$ & 10 & $282(7.5)$ & \multirow{3}{*}{0.654} & 26 & \multirow{3}{*}{0.422} \\
\hline $76-199 \mathrm{ft}$ & 10 & $640(10.1)$ & & 63 & \\
\hline$\geq 200$ & 11 & $333(6.9)$ & & 21 & \\
\hline \multicolumn{6}{|c|}{ Number acres corn planted } \\
\hline$\leq 140$ acres & 10 & $159(5.9)$ & \multirow{3}{*}{0.133} & $11(4.1)$ & \multirow{3}{*}{0.074} \\
\hline $141-335$ acres & 10 & $359(8.1)$ & & $43(6.0)$ & \\
\hline$\geq 336$ acres & 11 & $950(7.6)$ & & $69(9.2)$ & \\
\hline \multicolumn{6}{|c|}{ Days applying corn pesticide } \\
\hline$\leq 2$ days & 16 & $241(6.7)$ & \multirow{2}{*}{0.182} & $20(5.3)$ & \multirow{2}{*}{0.150} \\
\hline$>2$ days & 15 & $651(8.5)$ & & $55(8.7)$ & \\
\hline \multicolumn{6}{|c|}{ Hours mixing corn pesticides } \\
\hline$\leq 5$ hours & 14 & $220(5.2)$ & \multirow{2}{*}{0.163} & $17(6.0)$ & \multirow{2}{*}{0.110} \\
\hline$>5$ hours & 17 & $623(9.6)$ & & $54(7.4)$ & \\
\hline \multicolumn{6}{|c|}{ Number acres soybeans planted } \\
\hline$\leq 90$ acres & 10 & $181(6.0)$ & \multirow{3}{*}{0.372} & $12(5.0)$ & \multirow{3}{*}{0.109} \\
\hline $91-300$ acres & 11 & $544(7.3)$ & & $37(6.2)$ & \\
\hline$\geq 301$ acres & 10 & $580(10.3)$ & & $76(8.5)$ & \\
\hline \multicolumn{6}{|c|}{ Days applying soybean pesticides } \\
\hline$\leq 2$ days & 17 & $257(8.3)$ & 0.221 & $20(6.2)$ & 0.128 \\
\hline$>2$ days & 14 & $644(6.8)$ & & $59(7.6)$ & \\
\hline Hours mixing soy & & & & & \\
\hline$\leq 2$ hours & 15 & $168(6.1)$ & 0.024 & $17(5.8)$ & 0.078 \\
\hline$>2$ hours & 16 & $850(7.3)$ & & $59(7.4)$ & \\
\hline Total acres spraye & & & & & \\
\hline$\leq 165$ & 10 & $209(6.5)$ & & $17(5.2)$ & \\
\hline $166-700$ & 11 & $233(7.7)$ & 0.081 & $22(6.7)$ & 0.086 \\
\hline$>700$ & 10 & $1273(6.6)$ & & $98(7.4)$ & \\
\hline Applied lawn pest & & & & & \\
\hline Yes & 8 & $686(6.4)$ & 0.373 & $45(4.4)$ & 0.587 \\
\hline No & 23 & $320(8.3)$ & & $28(8.3)$ & \\
\hline
\end{tabular}

${ }^{\mathrm{a}} P$ value $<0.05$ obtained from ANOVA. 
(b)

\begin{tabular}{|c|c|c|c|c|c|}
\hline Variable & No. of Subjects & GM(GSD) & $P$ value & GM(GSD) & $P$ value \\
\hline \multicolumn{6}{|c|}{ Mix and load pesticides } \\
\hline Self & 10 & $918(7.8)$ & \multirow{2}{*}{0.110} & $105(6.9)$ & \multirow{2}{*}{0.019} \\
\hline Commercial & 21 & $259(7.1)$ & & $19(5.8)$ & \\
\hline \multicolumn{6}{|l|}{ Apply pesticides } \\
\hline Self & 10 & $966(7.5)$ & \multirow{2}{*}{0.089} & $108(6.7)$ & \multirow{2}{*}{0.016} \\
\hline Commercial & 21 & $253(7.1)$ & & $18(5.8)$ & \\
\hline \multicolumn{6}{|c|}{ Cab on tractor or application vehicle } \\
\hline Yes & 10 & $659(10.5)$ & \multirow{2}{*}{0.333} & $67(6.5)$ & \multirow{2}{*}{0.161} \\
\hline No & 21 & $303(6.7)$ & & $23(7.1)$ & \\
\hline \multicolumn{6}{|c|}{ Wear protective gloves } \\
\hline Yes & 17 & $330(8.3)$ & \multirow{2}{*}{0.607} & $38(8.0)$ & \multirow{2}{*}{0.630} \\
\hline No & 14 & $482(7.6)$ & & $27(6.5)$ & \\
\hline \multicolumn{6}{|l|}{ Wear long pants } \\
\hline Yes & 14 & $522(7.2)$ & \multirow{2}{*}{0.482} & $54(8.4)$ & \multirow{2}{*}{0.193} \\
\hline No & 17 & $306(8.5)$ & & $21(5.8)$ & \\
\hline \multicolumn{6}{|c|}{ Wear long-sleeved shirt } \\
\hline Yes & 11 & $552(7.9)$ & \multirow{2}{*}{0.492} & $46(8.5)$ & \multirow{2}{*}{0.467} \\
\hline No & 20 & $322(7.9)$ & & $27(6.6)$ & \\
\hline \multicolumn{6}{|c|}{ Change work clothes } \\
\hline Outside home & 15 & $556(11.3)$ & \multirow{2}{*}{0.358} & $48(9.5)$ & \multirow{2}{*}{0.304} \\
\hline Inside home & 16 & $279(5.1)$ & & $23(5.1)$ & \\
\hline \multicolumn{6}{|c|}{ Bring work clothes inside home } \\
\hline Yes & 20 & $528(7.9)$ & \multirow{2}{*}{0.273} & $37(6.6)$ & 0627 \\
\hline No & 11 & $224(7.3)$ & & $26(8.8)$ & 0.021 \\
\hline Change work sho & & & & & \\
\hline Outside home & 18 & $631(10.6)$ & 0126 & $39(7.4)$ & 0.512 \\
\hline Inside home & 13 & $200(3.8)$ & 0.120 & $25(7.0)$ & 0.012 \\
\hline Bring work shoes & & & & & \\
\hline Yes & 18 & $510(6.9)$ & 0.398 & $42(7.2)$ & 0.421 \\
\hline No & 13 & $268(9.2)$ & & $23(7.2)$ & \\
\hline Number times/m & & & & & \\
\hline$\leq 2$ & 5 & $400(7.4)$ & 0.976 & $34(10.6)$ & 0.942 \\
\hline$>2$ & 26 & $388(8.1)$ & טינס & $32(6.7)$ & 20. \\
\hline Number times/m & & & & & \\
\hline$\leq 2$ & 5 & $254(9.6)$ & 0618 & $37(11.8)$ & 0875 \\
\hline$>2$ & 26 & $423(7.7)$ & 0.010 & $32(6.7)$ & 0.078 \\
\hline Laundry work clo & & & & & \\
\hline Yes & 13 & $584(7.8)$ & 0201 & $52(9.2)$ & 0875 \\
\hline No & 18 & $222(7.2)$ & 0.201 & $17(3.9)$ & . \\
\hline Have dog and allo & & & & & \\
\hline Yes & 9 & $732(9.8)$ & 0.281 & $86(8.7)$ & 0.076 \\
\hline No & 22 & $322(7.0)$ & & $22(5.9)$ & \\
\hline Have cat and allor & & & & & \\
\hline Yes & 3 & $365(27.1)$ & 0954 & $49(7.5)$ & 0715 \\
\hline No & 28 & $392(7.1)$ & 0.934 & $31(7.3)$ & 0.115 \\
\hline
\end{tabular}

the small size of the study limits its ability to detect moderate differences in pesticide levels across groups.

Atrazine may have been transported into the study participants' homes in a variety of ways. Since all of the homes were located only a short distance from cropland upon which atrazine had been applied, atrazine could have entered the homes via droplets or adsorbed onto airborne dust particles. This mechanism is supported by finding that atrazine was found even in homes where commercial applicators had applied atrazine to the fields. No air samples were collected in this study in order to evaluate airborne migration of atrazine inside homes. Curwin et al. [17] collected air samples inside 
and outside the homes in his study and none of them were detectable for atrazine. However, the samples were only collected for a 24-hour period and this may not have been of sufficient duration to collect enough atrazine on the samplers to exceed the analytical limit of detection. However, the fact that atrazine levels were higher in homes where farmers had applied it themselves and applied greater quantities to more cropland, indicates that bringing atrazine inside the homes on contaminated clothing and shoes may also be a mechanism of in-home migration. Family members and pets, who likely spend time in and around cropland, farm equipment, and mixing areas, may also have brought pesticides into the home.

This study is novel in that it measured in-home atrazine concentrations long after planting season had ended, showing its persistence. This indicates that atrazine continues to be transported into homes long after application is over or that it does not degrade in the indoor environment as quickly as it does outdoors. Subsequent years of atrazine application could result in accumulation inside homes irrespective of the farmer's pesticide handling and spraying practices and could become a long-term exposure concern. Another strength of this study is its evaluation of a number of factors which may have influenced in-home migration.

However, this study had several limitations. It was a small study of only 32 homes and was unable to thoroughly evaluate the influence and correlation of hygiene and work practices on in-home atrazine levels. Also, atrazine exposure pathways on food and water were not evaluated. Food was potentially a source of pesticide exposure in farm families, but beyond asking questions about use of atrazine on participants' gardens (none of them used it on their gardens), no data were collected on food pesticide residues. Also, deposition of atrazine on family members clothing and skin could be a significant route of exposure and in-home migration, but no effort was made to measure atrazine on their clothing or skin.

\section{Conclusions}

This study found that all homes using the pesticide atrazine and employing a variety of hygiene and work practices have in-home migration of the pesticide. Although concentrations had significantly decreased several months after application, they were still detectable indicating long-term exposure of family members. The in-home atrazine concentrations are being correlated with atrazine metabolite levels in family members' urine and will be presented in a future publication. Further evaluations of the mechanisms by which atrazine may be migrating into farmers homes will guide interventions to reduce these long-term exposures.

\section{Acknowledgments}

The authors would like to thank everyone who helped with the data collection and analysis for this study, in particular Mr. Craig Taylor and Dr. Kevin Kelly at the Department of Occupational and Environmental Health at the University of Iowa and Dr. Dana Barr of the Centers for Disease Control and Prevention for their assistance. This study was supported by the University of Iowa's Heartland Center for Occupational Health and Safety (HCOHS) and Great Plains Center for Agricultural Health. This research study was supported (in part) by a pilot project research training grant from the HCOHS. The Heartland Center, an Education and Research Center, is supported by Training Grant no. T42/CCT 717547 from the Centers for Disease Control and Prevention/National Institute for Occupational Safety and Health.

\section{References}

[1] EPA, Pesticide Industry Sales and Usage: 2000 and 2001 Market Estimates, Office of Pesticide Programs, Office of Prevention, Pesticides and Toxic Substances, U.S. Environmental Protection Agency, Washington, DC, USA, 2001.

[2] M. C. R. Alavanja, D. P. Sandler, S. B. McMaster et al., "The agricultural health study," Environmental Health Perspectives, vol. 104, no. 4, pp. 362-369, 1996.

[3] R. G. Lewis, C. R. Fortune, F. T. Blanchard, and D. E. Camann, "Movement and deposition of two organophosphorus pesticides within a residence after interior and exterior applications," Journal of the Air and Waste Management Association, vol. 51, no. 3, pp. 339-351, 2001.

[4] B. Eskenazi, A. Bradman, and R. Castorina, "Exposures of children to organophosphate pesticides and their potential adverse health effects," Environmental Health Perspectives, vol. 107, no. 3, pp. 409-419, 1999.

[5] J. J. Quackenboss, E. D. Pellizzari, P. Shubat et al., "Design strategy for assessing multi-pathway exposure for children: the Minnesota Children's Pesticide Exposure Study (MNCPES)," Journal of Exposure Analysis and Environmental Epidemiology, vol. 10, no. 2, pp. 145-158, 2000.

[6] M. A. Bradman, M. E. Harnly, W. Draper et al., "Pesticide exposures to children from California's Central Valley: results of a pilot study," Journal of Exposure Analysis and Environmental Epidemiology, vol. 7, no. 2, pp. 217-234, 1997.

[7] D. E. Camann, G. G. Akland, J. D. Buckley, A. E. Bond, and D. T. Mage, "Carpet dust and pesticide exposure of farm children," in Proceedings of the International Society of Experimental Analysis Annual Meeting, Research Triangle Park, NC, USA, November 1997.

[8] N. J. Simcox, R. A. Fenske, S. A. Wolz, I. C. Lee, and D. A. Kalman, "Pesticides in household dust and soil: exposure pathways for children of agricultural families," Environmental Health Perspectives, vol. 103, no. 12, pp. 1126-1134, 1995.

[9] R. A. Fenske, J. C. Kissel, C. Lu et al., "Biologically based pesticide dose estimates for children in an agricultural community," Environmental Health Perspectives, vol. 108, no. 6, pp. 515-520, 2000.

[10] R. A. Fenske, C. Lu, J. Kissel et al., "Pesticide exposure of children in agricultural communities: exposure pathways and biologically based dose estimates," Program and Abstracts, Agricultural Safety and Health in a New Century, Cooperstown, NY, USA, 2000.

[11] L. Mott, D. Fore, J. Curtis, and G. Solomon, "NRDC reports: our children at risk: the 5 worst environmental threats to their health," Tech. Rep., NRDC, 1997.

[12] M. G. Nishioka, R. G. Lewis, M. C. Brinkman, H. M. Burkholder, C. E. Hines, and J. R. Menkedick, "Distribution of 2,4-D in air and on surfaces inside residences after lawn 
applications: comparing exposure estimates from various media for young children," Environmental Health Perspectives, vol. 109, no. 11, pp. 1185-1191, 2001.

[13] C. L. Curl, R. A. Fenske, J. C. Kissel et al., "Evaluation of takehome organophosphorus pesticide exposure among agricultural workers and their children," Environmental Health Perspectives, vol. 110, no. 12, pp. A787-A792, 2002.

[14] S. J. Reynolds, J. A. Merchant, A. M. Stromquist et al., "Keokuk county Iowa rural health study: self-reported use of pesticides and protective equipment," Journal of Agricultural Safety and Health, pp. 67-77, 1998.

[15] J. S. Colt, S. H. Zahm, D. E. Camann, and P. Hartge, "Comparison of pesticides and other compounds in carpet dust samples collected from used vacuum cleaner bags and from a high-volume surface sampler," Environmental Health Perspectives, vol. 106, no. 11, pp. 721-724, 1998.

[16] R. G. Lewis, R. C. Fortmann, and D. E. Camann, "Evaluation of methods for monitoring the potential exposure of small children to pesticides in the residential environment," Archives of Environmental Contamination and Toxicology, vol. 26, no. 1, pp. 37-46, 1994.

[17] B. D. Curwin, M. J. Hein, W. T. Sanderson et al., "Pesticide contamination inside farm and nonfarm homes," Journal of Occupational and Environmental Hygiene, vol. 2, no. 7, pp. 357-367, 2005.

[18] B. Curwin, W. Sanderson, S. Reynolds, M. Hein, and M. Alavanja, "Pesticide use and practices in an Iowa farm family pesticide exposure study," Journal of Agricultural Safety and Health, vol. 8, no. 4, pp. 423-433, 2002.

[19] P. J. Lioy, R. D. Edwards, N. Freeman et al., "House dust levels of selected insecticides and a herbicide measured by the EL and LWW samplers and comparisons to hand rinses and urine metabolites," Journal of Exposure Analysis and Environmental Epidemiology, vol. 10, no. 4, pp. 327-340, 2000.

[20] ASTM, "Standard Practice for the collection of floor dust for chemical analysis," Standard Practice D5438-00, American Society for Testing and Materials, Philadelphia, Pa, USA, 2000.

[21] B. D. Curwin, M. J. Hein, W. T. Sanderson et al., "Urinary pesticide concentrations among children, mothers and fathers living in farm and non-farm households in Iowa," Annals of Occupational Hygiene, vol. 51, no. 1, pp. 53-65, 2007.

[22] C. T. Ramwell, P. D. Johnson, A. B. A. Boxall, and D. A. Rimmer, "Pesticide residues on the external surfaces of field crop sprayers: occupational exposure," Annals of Occupational Hygiene, vol. 49, no. 4, pp. 345-350, 2005. 


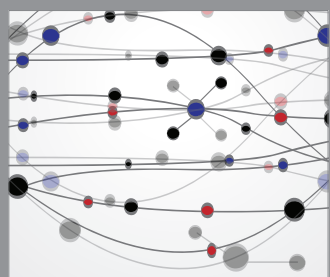

The Scientific World Journal
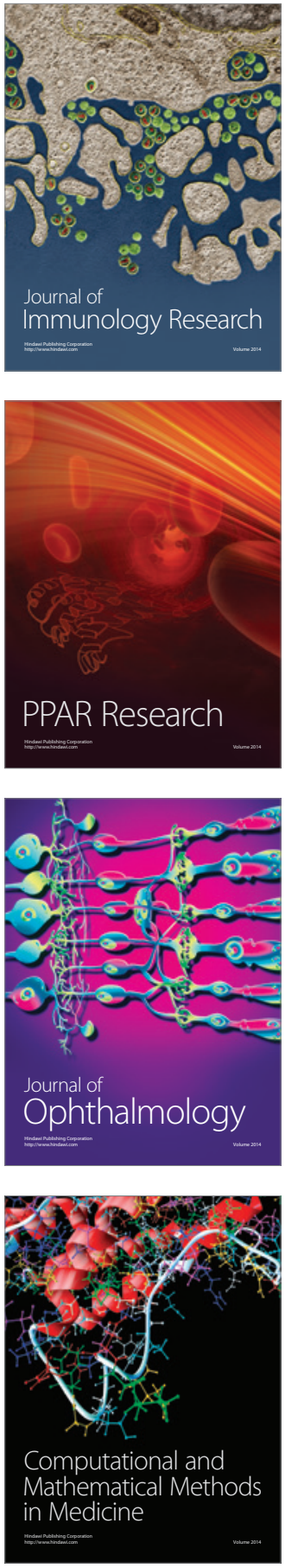

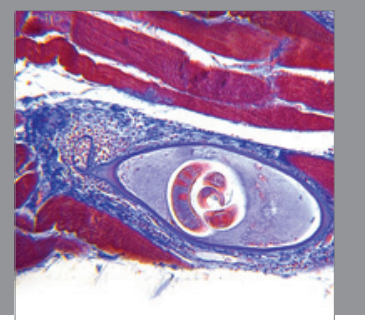

Gastroenterology

Research and Practice
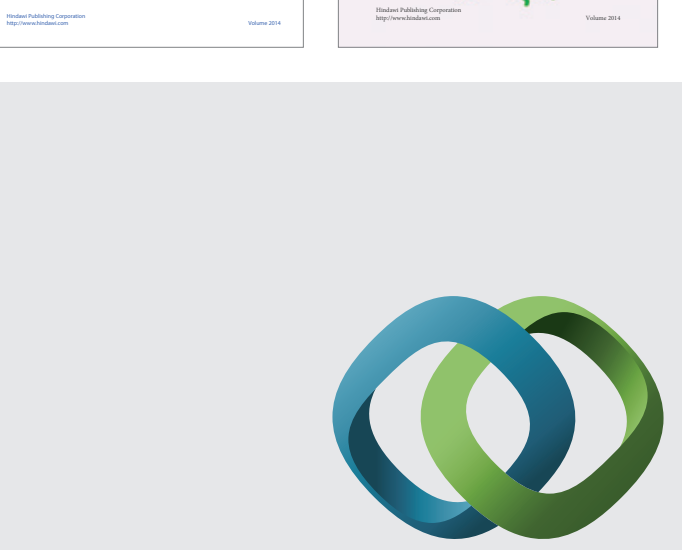

\section{Hindawi}

Submit your manuscripts at

http://www.hindawi.com
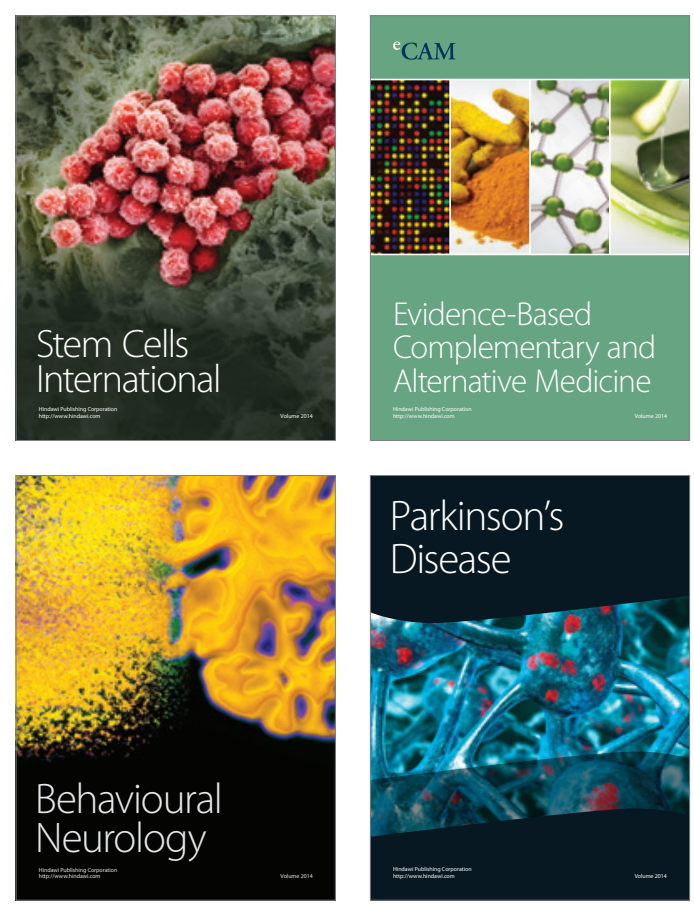

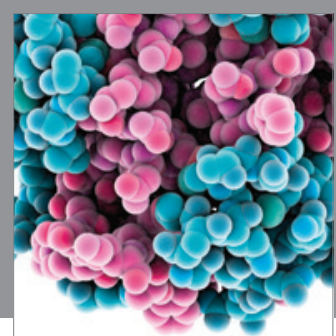

Journal of
Diabetes Research

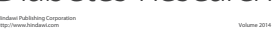

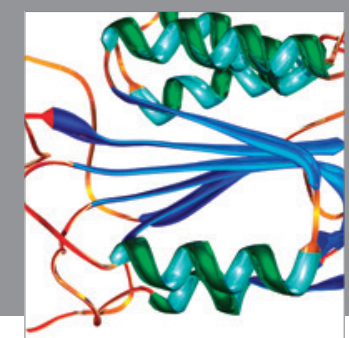

Disease Markers
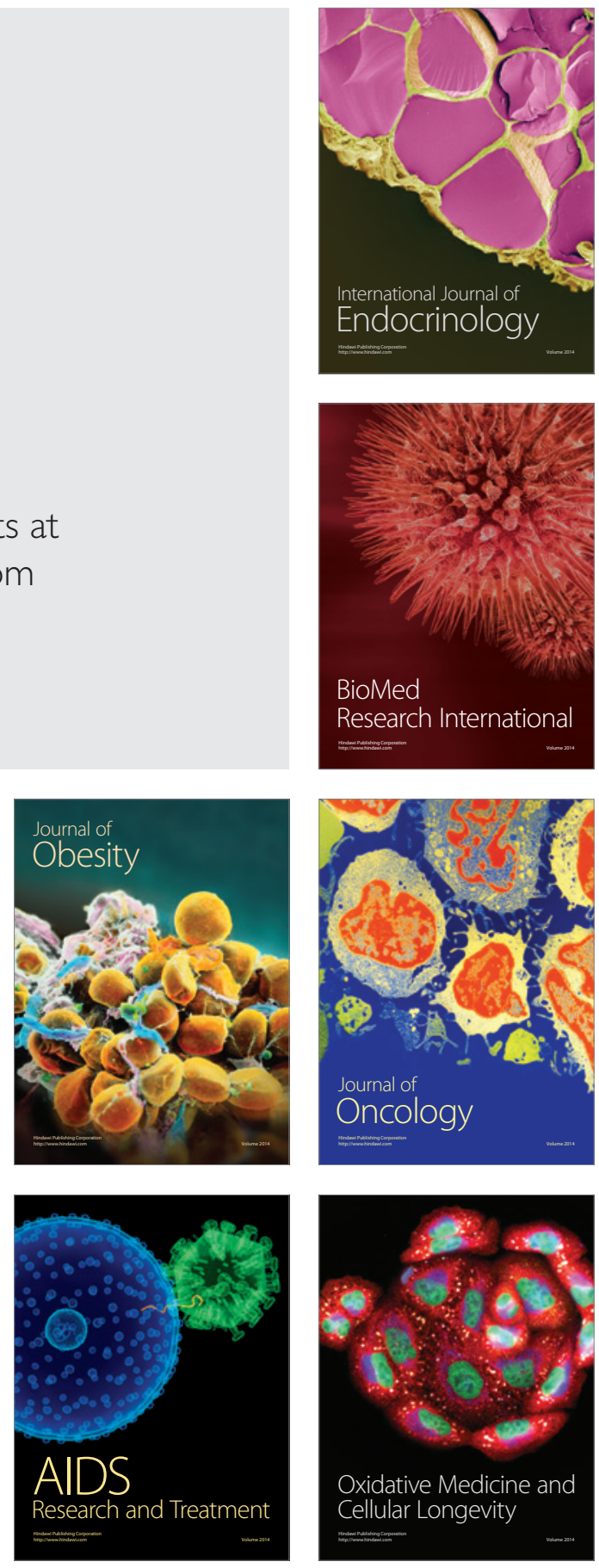